\title{
Strategies to modulate the intestinal microbiota and their effects on nutrient utilization, performance, and health of poultry
}

\author{
Sudhir Yadav and Rajesh Jha (10
}

\begin{abstract}
Poultry is widely produced and consumed meat globally. Its demand is expected to continue increasing to meet the animal protein requirement for ever-increasing human population. Thus, the challenge that poultry scientists and industry face are to produce sufficient amount of poultry meat in the most efficient way. In the past, using antibiotics to promote the growth of poultry and manage gut microbiota was a norm. However, due to concerns over potential fatalistic impacts on food animals and indirectly to humans, their use as feed additives are banned or regulated in several jurisdictions. In this changed context, several alternative strategies have been proposed with some success that mimics the functions of antibiotics as growth promoters and modulate gut microbiota for their beneficial roles. These include the use of probiotics, prebiotics, organic acids, and exogenous enzyme, among others. Gut microbiota and their metabolic products improve nutrient digestion, absorption, metabolism, and overall health and growth performance of poultry. This paper reviews the available information on the effect of feed additives used to modulate intestinal microbiota of poultry and their effects on overall health and growth performance. Understanding these functions and interactions will help to develop new dietary and managerial strategies that will ultimately lead to enhanced feed utilization and improved growth performance of poultry. This review will help future researchers and industry to identify alternative feed ingredients having properties like prebiotics, probiotics, organic acids, and exogenous enzymes.
\end{abstract}

Keywords: Enzymes, Microbiota, Organic acids, Poultry, Prebiotics, Probiotics

\section{Introduction}

The poultry industry is one of the fastest growing meat producing animal industries. Feed efficiency and high performance of the birds are the crucial goals in poultry production. Also, the quality of diet along with environmental conditions and health of birds need to be considered to achieve these goals. Conventionally, prime poultry feed ingredients are corn and soybean meal (SBM). Despite a rigorous search of alternative feedstuffs, nutritionists have yet not been able to find an alternative that can completely replace corn and SBM, although wheat is included in prominent levels in some parts of the world. There has been remarkable progress in the use of alternative

\footnotetext{
* Correspondence: rjha@hawaii.edu

Department of Human Nutrition, Food and Animal Sciences, College of Tropical Agriculture and Human Resources, University of Hawaii at Manoa, 1955 East-West Rd, Honolulu, HI 96822, USA
}

feedstuffs like coproducts, which are typically rich in fiber. Dietary fibers have been found to influence the gut microbial ecology [1]. Feed is possibly the most vital factor in exposing the internal body organs with the external environment via the gastrointestinal tract (GIT). The GIT of poultry is home to a complex and dynamic microbial community [2]. Culture-independent molecular techniques have been used in recent years to characterize microbial diversity and have opened the possibility to study the effect of environmental factors on these microbiota. The principal environmental factor is the diet. The initial studies have revealed ground-breaking results on the interaction of diet with microbiota such as microbial communities shift [3], the energy source for bacteria and selective growth of target bacteria [4]. Gut microbiota interacts within themselves, with their host, and with the diet of the host, whereas commensal bacteria play a

(c) The Author(s). 2019 Open Access This article is distributed under the terms of the Creative Commons Attribution 4.0 International License (http://creativecommons.org/licenses/by/4.0/), which permits unrestricted use, distribution, and reproduction in any medium, provided you give appropriate credit to the original author(s) and the source, provide a link to the Creative Commons license, and indicate if changes were made. The Creative Commons Public Domain Dedication waiver (http://creativecommons.org/publicdomain/zero/1.0/) applies to the data made available in this article, unless otherwise stated. 
pivotal role in host health and metabolism, and pathogenic bacteria cause direct or indirect harmful effects. Thus, feed ingredients should be selected to favor gut condition and maintain a balance between the environment, host, and microbiota. The total number of bacteria in the GIT is higher than the number of eukaryotic cells of the host body. According to Aland and Madec [5], bacteria in the host is divided to three types: dominant bacteria (> $10^{6} \mathrm{CFU} / \mathrm{g}$ sample), subdominant bacteria $\left(10^{3}\right.$ to $10^{6}$ $\mathrm{CFU} / \mathrm{g}$ sample $)$ and residual bacteria $\left(<10^{3} \mathrm{CFU} / \mathrm{g}\right.$ sample). The poultry GIT consists of a substantial proportion of Gram-positive, mainly facultative anaerobes from crop to lower ileum, whereas the ceca are composed of Lactobacillus, Enterococcus, coliforms, and yeasts [6-8]. In the proventriculus and gizzard, low $\mathrm{pH}$ causes a decrease in the bacterial population. In the duodenum, enzymes, high oxygen pressure, and bile salts are responsible for a reduction in microbial concentration whereas, in the lower small intestine and large intestine, the environment is favorable for the growth of diverse microbiota. Oviedo-Rondón et al. [9] defined beneficial gut microbiota having a protective role as the first line of defense against pathogenic bacteria in addition to assistance in specific metabolism and gut structure integrity. Both intestinal and cecal bacterial communities change and were found to diversify with age $[10,11]$. Apajalahti et al. [12] reported that the ileum and ceca have a favorable environment for bacterial growth and have as high as $10^{9}$ to $10^{11}$ bacteria per gram of content, respectively. The authors found 640 distinct species and 140 bacterial genera in the GIT of poultry, where about $90 \%$ of the species are yet to be described.

The GIT bacterial succession starts immediately after hatching and the settlement/colonization of microbiota depends on the egg microbial condition and contamination from hen during laying. Also, the species of bacteria in the GIT is determined during laying depending upon their ability to colonize and their interaction in the GIT $[12,13]$. The microbial community (MC) keeps changing throughout maturation of birds and is influenced by several factors including chicken strain, sex, and the rearing environment, within and between individual birds [2]. As the host grows, the microbiota becomes more diverse and tends to be relatively stable in older age. Increased breeding density and thermal stress increase harmful bacteria over beneficial ones [14]. Using environmental factors to modulate the intestinal microbiota is quite irregular and variable to control; instead, gut microbiota populations changes dramatically with the change in composition or density of nutrient as they are potential substrates for bacterial growth.

Diet plays a crucial role in the gut health of host by modulating the GIT bacteria, which can cause either a positive or negative effect on the host, depending on the type of diet [1]. The presence of water-soluble non-starch polysaccharides (WS-NSP) leads to a change in gut microbiota population and diversity. Mathlouthi et al. [15] found an increase in Lactobacillus and coliforms along with other facultative bacteria population when the bird's diet was switched from corn-based to wheat and barley-based. In case of WS-NSP rich diets, the increase in viscosity of digestive content and transit time is noticed along with a higher production of short chain fatty acids (SCFAs) which beneficially regulate ileal motility [16]. Change in gut microbiota with antibiotic supplements in a day-old bird shows an adverse effect on immune system development [17].

It can be noted that the host has multiple ways to control intestinal microbial growth and proliferation. However, the interaction among microbiota and between the microbiota and host mucosa is imperative to maintain gut environment balance. The intervention of dietary factors should consider all these interactions and mechanisms and their relationships with each other. This review discusses the gastrointestinal microbiota in poultry, their positive and negative roles, balance in gut ecology, and different strategies to modulate gut microbiota to improve the health and performance of the poultry.

\section{The gut microbiota of poultry}

The GIT of poultry consists of the esophagus, crop, proventriculus, gizzard, duodenum, jejunum, ileum, cecum, colon, and cloaca. Poultry GIT is much shorter as compared to other mammals relative to their body length. Thus, microbiota that grows in such a small GIT with relatively low transit time requires unique adaptations to adhere to the mucosal wall and to proliferate. The ceca have lower passage rate and are favorable to diverse groups of bacteria, which affect nutrient utilization and overall health of poultry.

\section{Identification and characterization of microbiota}

There are different techniques used to identify and characterize intestinal microbiota such as culture-based, G $+\mathrm{C}$ profiling, quantitative PCR, 16S rRNA bases studies, high-throughput sequencing, metagenome shotgun sequencing, and metaproteomic [18]. These microbiota studies started in the 1970s with culture-dependent techniques [19]. Some of the problems with these culture-dependent methods include: only culture selected bacteria out of the diverse digestive microbiota; lack phylogenetically-based classification scheme; unable to detect those present in very low abundance; and bacterial species live in a community and are dependent on one another as well as to the host environment. Therefore, isolating and growing in any selected culture might not be the same as in the host intestinal ecology [12]. To overcome these difficulties and limitations in selective culture, and to identify individual bacteria, the modern approach of examining the microbial 
DNA extracted from the sample using culture-independent techniques are carried out $[2,18]$. Molecular techniques are following the culture method in a contest of increment and diversification of complex microbiota during a different phase of life. These advanced techniques revealed that 90\% of the bacteria in the chicken GIT were previously unknown species [18]. Among the molecular techniques, the terminal restriction fragment length polymorphism (TRFLP) was used to compare and contrast microbiota in the duodenum, jejunum, ileum, and ceca [20]. Techniques such as metagenomic shotgun sequencing provide a more in-depth understanding of microbiota functionality in specific environments with strong differentiation between treatments microbiota profile [21]. Similarly, next-generation sequencing has made it possible to determine microbiota dynamics with increased coverage and accuracy [22]. Sequence data are further analyzed by Roche 454-pyrosequencing, Illumina MiSeq, HiSeq, and Ion PGM. Taxonomic assignments were done using QIIME and compare with the public databases like GreenGenes, the ribosomal database project (RDP) and SILVA. Further its followed by functional predictions using PICRUSt and Tax4Fun [23]. Stanley et al. [24] concluded that accurate profiling of microbiota could be done only with a controlled environment, from the day of hatch which essentially determines future microbiota too.

\section{The composition of gut microbiota}

The gastrointestinal tract of poultry, the most extensive body surface exposed to environmental influence, is the home of complex and highly diversified molecularly defined microbiota, containing an enormous number of different species that can be called the microbial community or microbiome. Composition and density of microbiota depend on the microbial composition of the inoculum introduced at hatch, first diet, and host intestinal epithelium [12]. The initial bacteria grow very fast, and the sterile environment soon becomes inhabited by $10^{8}$ and $10^{10}$ bacteria per gram of digesta in ileum and cecum, respectively in day 1-3 [12]. The authors also found that the bacterial density reached a maximum in a different section of GIT within the first week of age. In a phylogenetic diversity census study of bacteria in the GIT of chicken, 915 species-equivalents operational taxonomic units (defined at 0.03 phylogenetic distances) were found where chicken sequences represent 117 established bacterial genera [25]. The GIT harbors more than 100 billion bacteria. It consists of several times more bacteria than some of the cell in the host body, including thousands of species dominated by anaerobic bacteria. According to Albazaz and Bal [26], 12 days old birds have around 10-15 times higher facultative and obligatory anaerobic bacteria than that of aerobic bacteria. In a healthy balanced microbial community, there are mostly beneficial gram-positive bacteria (at least $85 \%$ of total bacteria), and remaining bacteria includes Clostridium in young birds and Salmonella, Campylobacter, and E. coli in older birds without any intestinal disturbance [27]. Some of the commonly found microbes in the GIT of poultry are Lactobacillus sp., Bacteroides sp., Eubacterium sp., Clostridium sp., Escherichia coli, Streptococcus sp., Prevotella sp., Fusobacterium sp., Selenomonas sp., Megasphaera sp., and Bifidobacterium sp. Commonly reported cecal microbiota of poultry are summarized in Table 1.

The MCs are distributed throughout the GIT of poultry, but due to differences in morphology, functionality, metabolic interactions, and microenvironment, regional heterogeneity in community composition is observed along the different GIT segments [28]. Also, the bacterial concentration gradually increases along the intestinal tract ranging from $10^{5}$ bacterial cells/g of luminal content in the duodenum to $10^{7}-10^{12}$ bacterial cells/g of luminal content in ileum to the colon, as is illustrated in Fig. 1. According to a recent study on the comparison between the lumen and mucosa-associated bacteria, the mucosa was found to have a highly rich microbial community of distinct group in ileum and cecum [29].

\section{Role of gut microbiota}

Gut microbiota of animals extensively interact with the host, diet, and within themselves [1]. Commensal gut microbiota plays a decisive role in maintaining the normal physiology of host animals. Some of the major roles are to help direct the normal formation or development of gut structure and morphology, boost immune responses, offers protection from luminal pathogens, as well as play an active role in digestion and utilization of nutrients [30]. Gut microbiota also has some direct and indirect harmful effects on chickens such as decrease digestibility of fat, increase cell turnover rate, production of toxic metabolites from the protein fermentation and may also lead to poor growth performance.

\section{Beneficial roles of gut microbiota}

Gut microbiota provides nutritional compounds to the host in the form of fermentation end-products and other secreted products such as SCFAs, specialized enzymes, amino acids, $\mathrm{B}$ and $\mathrm{K}$ vitamins and absorption of ions [7, 8, $31,32]$. Commensal bacteria generate SCFAs such as acetate, propionate, butyrate, and lactate in the GIT of chickens $[19,33]$. These SCFAs have their specific role in the GIT such as contribution to energy by gluconeogenesis [34] and reducing undesirable bacterial species in the cecum [32]. SCFAs also stimulate gut epithelial cell proliferation, differentiation and increases the villus height, thereby increasing the absorptive surface area [34]. Acetate and propionate also act as an energy substrate for tissues. Recently, xylanase genes are isolated and overexpressed from the cecum of chickens which can degrade and digest complex 
Table 1 Presence of dominant microbiota in the ceca of chicken

\begin{tabular}{|c|c|c|c|}
\hline Dominant microbiota & Reference & No. of genera & Comments \\
\hline $\begin{array}{l}\text { Firmicutes, Bacteroidetes, and Proteobacteria (> 90\%) } \\
\text { Peptostreptococcus, Propionibacterium, Eubacterium, } \\
\text { Bacteroides, and Clostridium }\end{array}$ & $\begin{array}{l}\text { Wei et al. } \\
\text { [25] }\end{array}$ & $\begin{array}{l}13 \text { phyla and } \\
117 \text { genera }\end{array}$ & $\begin{array}{l}\text { > } 900 \text { species-equivalent OTUs, defined } \\
\text { at } 0.03 \text { phylogenetic distance }\end{array}$ \\
\hline $\begin{array}{l}\text { Blautia, Faecalibacterium, and Anaerotruncus (dominant } \\
\text { in the reused litter) } \\
\text { Escherichia/Shigella, Lactobacillus, Bacteroides, and } \\
\text { Subdoligranulum (dominant in the fresh litter) }\end{array}$ & $\begin{array}{l}\text { Wang et al. } \\
{[98]}\end{array}$ & $\begin{array}{l}133 \text { OTUs within } 41 \\
\text { genera considered }\end{array}$ & $\begin{array}{l}\text { Genera differed between the fresh and } \\
\text { reused litter for the cecal digesta samples } \\
\text { More abundance in d } 10 \text { than d } 35\end{array}$ \\
\hline $\begin{array}{l}10 \% \text { previously known species, } 35 \% \text { previously known } \\
\text { genus but unknown species, and } 55 \% \text { unknown genus }\end{array}$ & Apajalahti et al. [12] & $\begin{array}{l}>640 \text { species } \\
\text { from } 140 \text { genera }\end{array}$ & $\begin{array}{l}\text { Consider bacterial community rather } \\
\text { than talking about individual species. }\end{array}$ \\
\hline $\begin{array}{l}\text { Clostridiaceaen (65\%), Fusobacterium (14\%), Lactobacillus } \\
\text { (8\%) and Bacteroides (5\%) }\end{array}$ & $\begin{array}{l}\text { Albazaz and Bal } \\
\text { [26] }\end{array}$ & & \\
\hline $\begin{array}{l}\text { Clostridium leptum (20\%), Clostridium coccoides (27\%), } \\
\text { Sporomusa sp. (21\%), and Gamma Proteobacteria groups } \\
(20 \%) \text {, Atopobium (3.6\%), Bacteroides (2\%), and } \\
\text { Bifidobacteria (1\%) }\end{array}$ & $\begin{array}{l}\text { Zhu et al. } \\
\text { [2] }\end{array}$ & & $\begin{array}{l}\text { Microbiota from ceca of mature birds } \\
\text { fed standard commercial diet }\end{array}$ \\
\hline $\begin{array}{l}\text { Lachnospiraceae (47\%), Ruminococcaceae (19\%), } \\
\text { Bifidobacterium (10\%), Lactobacillus (10\%), } \\
\text { Coriobacteriaceae (7\%), Bacteroides (2\%) } \\
\text { and others (5\%) }\end{array}$ & $\begin{array}{l}\text { Apajalahti and } \\
\text { Vienola } \\
\text { [43] }\end{array}$ & & $\begin{array}{l}\text { Average cecal microbiota composition } \\
\text { of commercial broiler chicken farms }\end{array}$ \\
\hline $\begin{array}{l}\text { Bacteroidetes (> 18\%), Tenericutes and Proteobacteria } \\
(1 \%-5 \%) \text { and at family level Ruminococcaceae, } \\
\text { Bacteroidaceae, uncultured Clostridiales, and } \\
\text { Streptococcaceae }\end{array}$ & $\begin{array}{l}\text { Witzig et al. } \\
\text { [99] }\end{array}$ & & Microbiota present in ceca \\
\hline $\begin{array}{l}\text { Fusobacterium prausnitzii, Ruminococci, Clostridia and E. } \\
\text { cecorum }\end{array}$ & $\begin{array}{l}\text { Gong et al. } \\
{[20]}\end{array}$ & & Present in cecal mucosa \\
\hline
\end{tabular}

substrate like non- starch polysaccharides which will encourage nutritionist and researchers to explore alternative feedstuffs to incorporate in large-scale industrial production [35].

Gut microbiota resists colonization of the chicken intestinal tract by pathogens and other non-indigenous microbes through competitive exclusion [7, 32, 36]. Attachment of non-pathogenic bacteria to the brush border of gut cell obstructs pathogens from attachment and entry into the cell. Indigenous microbiota of the gut suppresses the growth of pathogens by secreting organic acids and bacteriocins through direct stimulation of the immune

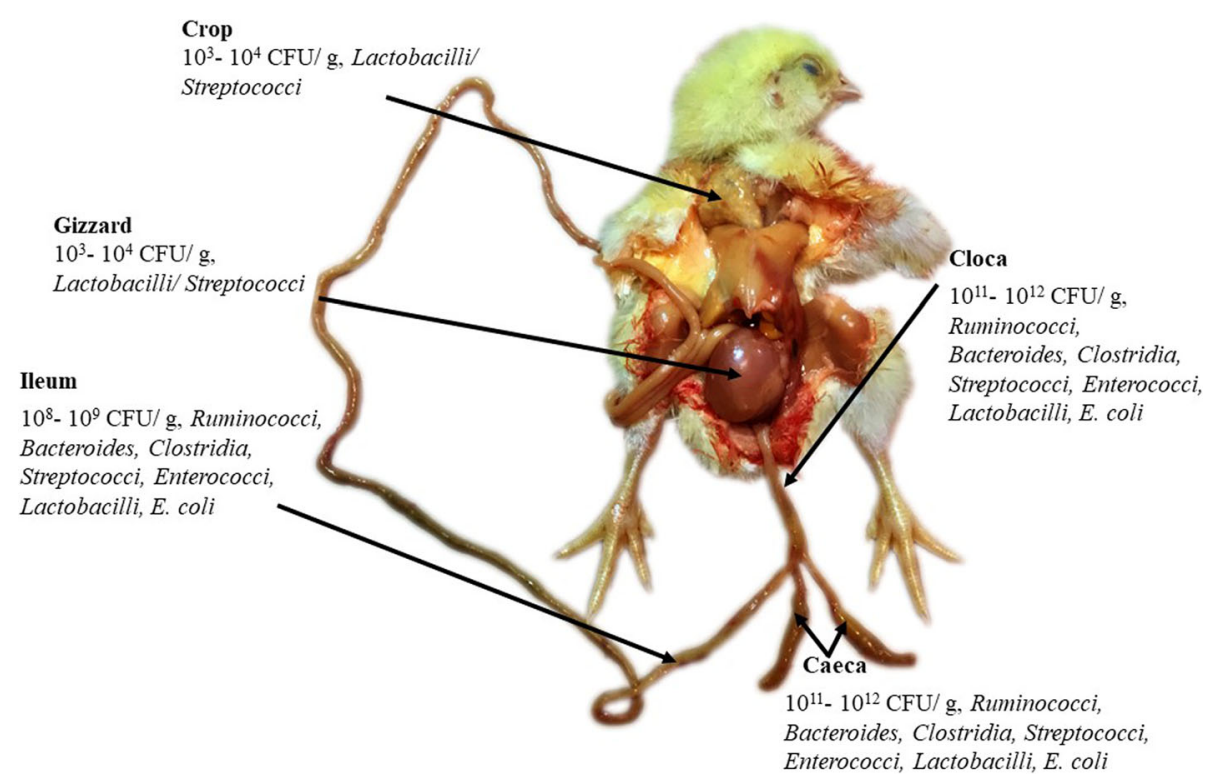

Fig. 1 The major bacterial habitats and concentration in the gastrointestinal tract of chicken 
system and compete for nutrition and attachment points to the mucosal wall [13]. In an in vitro experiment by Naidu et al. [37], Lactobacillus producing bacteriocin Reuterin was found effective in inhibiting the growth of Salmonella, Shigella, Clostridium, and Listeria. Increasing these types of useful bacteria along with substrates for their proliferation and metabolism improve feed intake and nutrient utilization by the host.

Experiments comparing conventionally reared versus germ-free animals show that commensal bacteria play a role in developing the intestinal host defenses, including the mucus layer, epithelial layer and lamina propria $[8,13$, 32]. The mucus layer keeps both commensal and pathogenic microbes away from animal tissues. If the mucus layer is crossed, the epithelium acts as a barrier to enter inside the host tissue. The underlying lamina propria provides antibodies, cytotoxic and helper T cells, and sometimes also phagocytic cells. These immune cells not only combat pathogenic bacteria but also control the overcrowding of normal microbiota. Researchers also found that the antibody response in chicken is antigen-driven [38, 39]. Further evidence suggests that the intestinal immune system develops parallel to the development of gut microbiota. Thus, gut microbiota plays a significant role in maintaining immune homeostasis by preventing inflammation [40].

\section{Harmful roles of gut microbiota}

Sometimes normal bacteria can have an adverse effect on gut health, even under ideal conditions. Commensal bacteria compete for nutrition with the host and produce toxic compounds as a byproduct of metabolism. The undigested protein of feed origin, true endogenous protein (mucin, epithelial cells, enzymes, and antibodies) and microbial proteins which bypass the small intestine and are available for the microbiota in the large intestine [41]. These microbiota ferment bypass proteins to produce toxic metabolites such as ammonia, amines, phenols, cresol and indoles which can impact intestinal cell turnover and even growth performance [41-43]. Also, any disorder to the epithelium of small intestine could lead to high protein level in the large intestine, resulting to increased protein fermentation and putrefaction as evidenced in a study [4]. In the study, birds challenged with Eimeria maxima showed elevation in biogenic amine level in the cecum, it might be due to disorder in integrity and absorptive capacity of the small intestine epithelium.

Despite several benefits to host, GIT microbiota can result in detrimental effects in certain special conditions. Intestinal microbes decrease fat digestibility by deconjugating bile acids $[8,42]$. Bile acids and their salts are required to emulsify and absorb fat in the intestine. Catabolism of the bile salts in the gut by a variety of microbiota causes a decrease in lipid absorption and produces toxic products that inhibit the growth of chicken. Many authors have proposed that the reduction in amino acid catabolism and bile catabolism and increase in availability of nutrients are the primary physiology of how antibiotics improve animal performance [7, 44, 45]. Microbiota alters the intestinal morphology, cell turnover rates, and mucus secretion $[8$, 42]. Conventionally raised animals have higher small intestine weight due to its thicker walls, longer villi, and deeper crypts which allow infiltration of immune and connective tissue as compared to germ-free animals [46, 47]. It is also believed that an increase in thickness of the GIT wall and connective tissue decreases the nutrient uptake $[7,45]$. Further, microbiota accelerates turnover rates of enterocytes and goblet cells such that the high cell turnover is accompanied by extremely high rates of metabolism and protein synthesis $[48,49]$. This higher rates of metabolism and protein synthesis results in higher populations of immature cells that are less efficient in absorbing nutrients and are less able to provide efficient barrier due to having looser tight junctions [42].

As discussed above, microbiota plays a crucial role in host immunity development. However, there is inherent inefficiency when immune stimulation is maintained at a constant level, as appears to be the case in germ-free chickens, which contain lower serum Immunoglobulin G (IgG) compared to conventionally grown chickens [50]. Thus, microbiota uses explicitly IgA and IgG secretion which alone can cost several hundred grams of protein in a lifetime that is not directed towards the growth of chicken. According to Macpherson et al. [51], IgA is directed towards individually established gut flora and maintaining its population constant by controlling species entering from food and the environment. In poultry, gut metabolism accounts for $20-36 \%$ of the whole-body energy expenditure, primarily related to cell turnover required by microbiota [49]. Thus, the efficiency of nutrients from feed has to be reduced to achieve improved growth performance.

\section{Balance in gut ecology}

The GIT of poultry harbors a complex and dynamic microbiome consists primarily of bacteria and low levels of protozoa, fungi, yeasts, bacteriophages, and viruses. These MCs intensively interact with the host and ingested feed. The composition of this microbiome is different in different parts of the GIT, with each section containing different niches. These MCs in different segments are affected by the flow of nutrients from the diet, the response by host immunity, other substances produced, and/or secreted making up this complex microbiome $[9,52]$. Oviedo-Rondón et al. [9] suggested that the cross-talk between microbiota and host regulates the degree of immunity, symbiotic relationship, and production of endogenous proteins in response to pathogenic antigens. Even if there is an overall positive balance established between the microbiota and the host, still microbiota are classified into commensal and 
pathogenic organisms. Usually, pathogenic microorganisms are present in low concentration and can remain in the gut for more extended periods without any harmful effect to the host. Although some of the microbiota show beneficial roles in promoting a stable gut environment, they can act as pathogenic agents by producing toxic metabolites when the situation is unfavorable. Thus, a stable environment in the gut is a key to a healthy host. In addition, OviedoRondón and Hume [53] explained the importance of maintaining the diversity of the gut $\mathrm{MC}$, which in turn, improve gut health for better feed conversion and nutrient utilization in birds. A better understanding of this $\mathrm{MC}$ results in improvements in poultry health, productivity, and a reduction of food-borne pathogens, welfare, and overall environmental impact of poultry production for a more sustainable industry.

\section{Effects of gut microbiota on nutrient utilization, growth, and health}

The GIT is the ultimate organ for host digestion and immunity and the proper functioning of this organ; gut microbiota should be in balance and dynamic state. Gut microbiota affects the metabolic processes directly such as Clostridium cluster XIV, and Ruminococcus can break cellulose and resistant starch [54]. Indirectly as most of the bacteria phylotypes abundant in higher AME utilizing and higher growth performing birds are firmly related to bacteria with known beneficial metabolic characteristics [55]. Also, the most dominant cecal microbes Firmicutes, and Bacteroidetes are correlated with body weight as their ratio is found significantly higher in obese hosts and lower in hosts of low to healthy body weight [56]. For proper intestinal function and integrity, bacterial fermentation plays an essential role by producing fermentation by-products such as SCFAs, especially butyrate, to provide energy to the epithelial cells and another SCFAs undergoes diffusion to enter different metabolic pathways. Other functions of SCFAs include regulation of intestinal blood flow, mucin production, enterocyte growth and proliferation, and intestinal immune responses [57]. Lactobacillus sp. is known to produce a variety of SCFAs and bacteriocins with bacteriostatic or bactericidal properties either by reducing $\mathrm{pH}$ or by modifying the receptors against pathogenic microbes [30].

\section{Modulating gut microbiota}

Some feed ingredients and additives are reported to modulate gut microbiota and immune system of the host [1]. Antibiotics have been used to modify gut microbiota and were revered by farmers as they promote growth performance of poultry. However, concern about antibiotic resistance and other negative impacts of the use of antibiotics as a growth promoter, have forced poultry farmers to stop or limit their use in feed. Feed additives and supplements like probiotics, prebiotics, organic acids, and exogenous enzymes are used as an alternative to antibiotics to the modulate the gut microbiota with some success.

\section{Antibiotics}

Antibiotics have been used for therapeutic and growth promoting prophylactic purposes in animals since the 1940s [58]. In a report by Oliver et al. [59], United States (US) alone uses about 24.6 million pounds of antibiotics annually, and most of these are used as a growth promoter rather than as a treatment of infections. Antibiotics are either synthetic drugs or are obtained from natural sources. These are used to kill or inhibit the growth of microorganisms in a broad sense, but these antibiotics also play some beneficial role in the gut. Early exposure of broiler chicken for short-term to the orally administered antibiotics (amoxicillin) has shown effects on the microbial colonization, mucosal gene expression and immune development in the later period up to 2 weeks post-hatch [17]. In a recent study by Wisselink et al. [60], adding antibiotics in drinking water changed the microbial community and immune parameters temporarily in the later phase of life (days 15 to 20). The dominant mechanism by which antibiotics work ranges from cell membrane destruction to reduction of growth-depressing metabolites produced by microbiota in the gut, especially ammonia and bile degradation products [61]. For the host, antibiotics have been shown to increase the nutrient availability in the gut that causes a decrease in amino acid catabolism and bile salts breakdown leading to an increase in the digestibility of dietary protein. Other beneficial effects of antibiotics include the efficient absorption of nutrients and nutrient utilization by the gut wall due to the thinner epithelium and decreased microbial use of nutrients; thus, more nutrients reach the host's tissues [61]. Because antibiotics reduce the gut microbiota and their toxic metabolites, antibiotics have been widely incorporated into the poultry industry for decades. At the same time, irregular use and overuse of these antibiotics have been claimed to lead to the development of resistance by bacteria. This bacterial resistance causes a threat to the human and animal treatment as they transmit the genes for antibiotic resistance or may also exchange plasmid with inter or intra-species [62]. Their use as the prophylactic dose in animal feed has been banned in some jurisdictions like in one of the European Union (EC Regulation, No. 1831/ 2003) while other jurisdictions are considering or have imposed strict regulation on use or gradual ban in animal farming. This prohibition has already added pressure to the poultry farmers and nutritionists. For example, there is evidence that antibiotic growth promoters (AGPs) were useful in the prevention of necrotic enteritis in poultry, ban in use of AGP has led to increased incidence of necrotic enteritis cases. Antibiotics are also known for its anti-inflammatory role with the benefit of reducing waste of energy and utilizing in production [61]. Thus, there is an immediate need 
for identifying alternatives to antibiotics to maintain the balance of the ecosystem in the gut as well as to improve the overall performance of the birds [63].

\section{Probiotics}

Probiotics also referred as direct-fed microbial (DFM), are single or mixed cultures of living non-pathogenic microorganisms, which, when administered in adequate amounts confers a health benefit on the host [64]. Bacterial species currently being used in probiotics are lactic acid bacteria (LAB), i.e., (L. bulgaricus, L. acidophilus, L. casei, L. lactis, L. salivarius, L. plantarum), Streptococcus thermophilus, Enterococcus faecium, E. faecalis, Bifidobacterium sp. [65]. In addition to bacteria, fungi (Aspergillus oryzae) and yeast (Saccharomyces cerevisiae) are also used as probiotics [65]. Their mode of action involves multiple mechanisms, including competitive exclusion, promoting gut maturation and integrity, regulating the immune system, preventing inflammation, improving metabolism, improving growth, improve the fatty acid profile and oxidative stability in fresh meat [66], and neutralizing enterotoxins. Singh et al. [67] found increased apparent metabolizable energy and protein digestibility of fibrous diets in broiler chickens when supplemented with DFM along with multi-enzymes. However, some researchers did not found significant effect of single or multiple-strains DFM on growth performance of chickens [68]. Multiple-strains DFM showed better effects on local and systemic immune responses and competitive exclusion compared to single-strains DFM [68] Also, Kalia et al. [69] observed no differences in the growth performance of the RIR cross-bred chicken that was selected as the best performing breed out of all the breeds used in the trial. This could be due to the difference in the dose or an insufficient number of probiotic bacteria, nature and route of probiotics administrated, the difference in microbes among a range of altitudes, and the variation in the physiological state of the birds $[63,69]$. Wang et al. [70] found that probiotics can improve gut microbiota diversity. Specifically, Bacillus sp. increased body weight and Pediococcus pentosaceus had higher average SCFAs content. They also identified that cecal microbiota, Bacteroidetes abundance was directly correlated with the content of propionate, butyrate, and isobutyrate, whereas the abundance of Firmicutes positively correlates acetate production in the cecum. Regarding immune responses, Brisbin et al. [71] reported that in the cecal tonsil cells of chicken, $L$. acidophilus induces T-helper cytokines whereas $L$. salivarius induces anti-inflammatory response more effectively. Also, the "Nurmi concept" is the most convenient example of an effective immune response by micro-organism whereby day-old chicks acquire enhanced protection against Salmonella infections when they are administered the complex microbiota of older chicks. In a study conducted by Cengiz et al. [72], no interaction was observed between stocking density and probiotic supplementation for performance, carcass yield, Salmonella and Lactobacillus population in the gut. Although, probiotics enhanced the performance during the starter phase only where high stocking density affected the birds negatively and stress indicators were not affected. Bai et al. [73] found that probiotics improve growth performance in early stage ( 1 to $21 \mathrm{~d}$ ) of a chicken, but there was no dose response for $22-42 \mathrm{~d}$ when feeding $0.1 \%$ to $0.3 \%$. As a result, the study recommended incorporating probiotics in $0.1 \%$ dose to chicks as an alternative to AGPs. Previously, $\mathrm{Li}$ et al. [74] also found that commercial probiotic mixture of yeasts and other microbes improve growth performance in starter age of broilers with no dose effect among $0.2 \%$ to $0.6 \%$. Based on the reports available so far, probiotics in feed can be considered as one of the best alternatives to antibiotics in poultry diets to modulate gut microbiota as well as promote overall health and growth performance.

\section{Prebiotics}

Prebiotics are non-digestible feed ingredients that are responsible for altering the composition and metabolism of gut microbiota selectively. Prebiotics has the ability to increase the number of bifidobacteria and other species that affect the health of host positively [63]. The $\beta$-glucan fed birds were found to have anti-Salmonella property by increasing the IgA-secreting cells, IgG level, and goblet cells causing immunomodulation to help birds boost immunity during Salmonella challenge [75]. Prebiotics also increase the number of the LAB in the gut that aid in the competitive exclusion of pathogens [76]. They also help to enhance defense mechanism. However, the mechanism by which they help in defense is not precise. It is supposed to increase the production of SCFAs leading to an acidic environment in the gut and suppresses pathogens, which also recover some lost energy from competition with bacteria [77]. According to Kim et al. [78], rapid clearance of pathogens because of prebiotic administration is a mechanism to boost immunity. In fact, prebiotics and probiotics have similar modes of action to maintain gut ecology and when provided in combination shows synergistic effect on the gut health [79]. Supplementation of slowly digestible prebiotics provides fermentable carbohydrates for microbiota in the distal large intestine, which in turn, suppress putrefaction. Owing to the supplementation of prebiotics in diet and its mechanism in the gut attributes to improvements in bird performance and energy utilization [27]. Though commonly used these days as an alternative to AGP, nature, characteristics, and type of prebiotic is crucial to understand as these variables influence the effects of the poultry. Commonly used prebiotics are oligosaccharides including inulin, fructooligosaccharides (FOS), mannanoligosaccharides (MOS), galactooligosaccharides, soya-oligxosaccharide s, xylo-oligosaccharides, pyrodextrins, and lactulose. The 
FOS is the preferred substrate for bifidobacteria, helping it to bind to the host mucosa leading to the hindrance of pathogenic bacteria attaching to the gut mucosa, whereas MOS binds pathogens and excretes them with the digesta flow $[63,78]$. Dietary supplementation with FOS also decreases $C$. perfringens and E. coli and increases Lactobacillus diversity in the chicken gut. The MOS also block binding of pathogenic bacteria notably Salmonella typhimurium to mannan receptors on the mucosal surface, thus prevent attachment or colonization [63]. Furthermore, developing method of a complete image of the GIT affected by pathogens using modern molecular techniques and bioinformatics pipeline will help understand the complex mode of action of prebiotics to control Salmonella [80]. Therefore, using preexisting prebiotics or developing new prebiotics can be a potential feed additive to replace AGP and modulate microbiota for better growth and improved health of poultry.

\section{Organic acids}

Organic acids are the normal constituents of the plant and animal tissues. Previously organic acids were used as a preservative to prevent deterioration and increase shelf-life of perishable food pre-harvest and post-harvest as it controls the microbial contamination [81]. It includes acids such as lactate, acetate, propionate, butyrate, tannic, fumaric, and caprylic acids, among others. These acids play a beneficial role in the gut health and performance of birds [82]. Saki et al. [82] found that organic acid increases the LAB count in the ileum and cecum of broiler chickens. The organic acid is also produced in the host gut after fermentation of carbohydrates, especially in the ceca of birds where the microbial population and diversity is at its highest level [63]. Each of these acids is utilized in different ways in the body of the host. Acetate is carried to the liver as an energy substrate for muscle tissue. Propionate is converted to glucose in the liver by the process of gluconeogenesis. Butyrate in small intestine enterocytes helps in the proliferation, development and serves as a vital source of energy for host metabolic activities [1]. However, butyrate does not always show positive effects, which largely depends on its location and concentration in the GIT [83]. The organic acids lower chyme $\mathrm{pH}$ which increases pepsin activity. The peptides arising from pepsin proteolysis trigger the release of hormones gastrin and cholecystokinin, which also helps to improve growth as this may increase protein digestion [84]. The mechanism of action could result in improved body weight gain and feed conversion ratio and decreased cumulative feed consumption [85], suppressing bacterial cell enzymes [63], and reduced pathogens like Enterobacteriaceae and Salmonella [82]. Supplementation of organic acids may affect cell membrane or cell macromolecules or interfere with nutrient transport and energy metabolism leading to the death of bacteria [81]. The effectiveness of these compounds as antimicrobial agents in the gut depends on the ability of acids to change from the un-dissociated to the dissociated form, the $\mathrm{pKa}$ value, and its hydrophobicity. Supplementation of these acids should be done in proper dose otherwise it will lead to depressed villus height and width, as well as crypt depth [86]. Thus, organic acids have been incorporated in feed or in water to affect positively on the prevention of GIT diseases, immunity, nutrient digestibility, and overall growth performance of the broiler chickens.

\section{Exogenous enzymes}

Enzymes are specialized proteins that catalyze or accelerate the chemical reaction. The enzyme activity may be substrate dependent or through the particular site on substrates such as fat, protein, or carbohydrate. Commonly used exogenous enzymes in poultry diets are $\beta$-glucanase, xylanase, amylase, $\alpha$-galactosidase, protease, lipase, and phytase [87]. The role of exogenous enzymes is to fulfill the absence of endogenous enzymes, to counter the anti-nutritional factors present in conventional and unconventional poultry diet. These exogenous enzymes, in combination with non-conventional ingredients, are used to reduce the cost of feeding and to utilize the non-conventional feed ingredients efficiently [88] as non-conventional feedstuffs are typically rich in fibers [1] and are not utilized by endogenous enzymes of poultry. Also, a portion of starch and protein of these non-conventional feedstuffs are entrapped in the fiber matrix, making it unavailable for endogenous enzymes of animals, but these nutrients can be made available for utilization by use of exogenous enzymes [89]. Accordingly, NSP degrading enzymes which produce oligosaccharides could also reduce the putrefaction in the cecum as bacteria prefer carbohydrate as a substrate for fermentation when both carbohydrate and protein are available in the gut [41].

Enzyme supplementation is also essential for environmental issues such as pollution of soil and water with nutrients, pathogens, fouling of environment and heavy metals which occurs due to poor excreta management, as it may reduce the pollutant potential of excreta [88]. Carbohydrase supplementation increases the proportion of lactic and organic acids, reduced ammonia production, and increased SCFA concentration which is indicative of hydrolysis fragmentation of NSP and supporting the growth of beneficial bacteria. Supplementation of multienzyme (xylanase, amylase, and protease) optimized the utilization of fibers, leading to better growth performance of broiler chicken [90]. In an experiment with barley-based diet, $\beta$-glucanase supplementation decreased ileal viscosity and affected SCFA concentration in the crop and ceca due to the shift in resident microbial activity. The role of $\beta$-glucanase in other 
segments of the GIT is unknown [91]. When exogenous enzymes were supplemented to degrade NSP in a barley-based diet, gut microbial communities varied significantly among gut sections except between the duodenum and jejunum [92]. Exogenous enzymes are also beneficial to control salmonella that is transferred horizontally. The efficiency of these exogenous enzymes depends upon the diet composition, animal strain, sex and age, and digesta flow rate also the type of enzyme supplemented [87, 93]. Yang et al. [93] reported the growth-promoting effects of enzymes linking it to the mucosal morphology of the small intestine. They also stated that the crypt depth of the jejunum was reduced along with an increase in the membrane enzyme activity and role in the last step of digestion causing the improved growth of chicken by supplementing xylanase in diets. Also, Cowieson et al. [94] noted the beneficial role of exogenous protease by decreasing undigested protein from diet or endogenously produced to reach the caudal gut reducing inflammation and maintaining tight junction integrity. Exogenous enzymes are multifactorial in action due to its role in the partitioning of nutrients and help in the growth of specific microbiota by producing nutrients for them [95]. These enzymes are being used as an integrated solution to reduce the economic burden not just by limiting GIT pathogens but also by reducing medication costs, variability in animal performance, and reducing mortality by improving the gut health [96]. Although the exogenous enzyme has many benefits to the poultry, there are still some limitations imposed to health condition, disease challenge, quality of feed, $\mathrm{pH}$ and digesta retention time in the GIT [97]. Therefore, nutritional strategies to overcome limitations could help in effective utilization of unconventional feed ingredients to produce cost-effective feed for broiler chickens.

\section{Conclusion}

To achieve optimal microbiota for better growth and improved health of poultry and to develop cost-effective feeding program, there is a need to manipulate gut microbiota through strategies such as the use of feed additives supplements singly or in combination in diets. Previously, antibiotics growth promoters were most commonly used to manipulate gut microbiota. Due to concern over the use of in-feed antibiotics, alternatives are being explored and applied. As alternatives, several feed additives including probiotics, prebiotics, organic acids, and exogenous enzymes are available and have been successfully used for modulating gut microbiota for better health and efficient production of poultry. Though recognized as a forgotten organ, gut microbiota is an essential component of intestinal ecology. A better understanding of gut microbiota and its interaction or balance with other organisms is crucial in understanding the composition of gut ecology, the effect of feed supplements on the modulation of gut microbiota, and finally, the beneficial and harmful effects of the microbiota. However, advanced techniques have only evolved in recent years. Therefore, there is only limited evidence available on how specific dietary components affect the gut microbiota. The main sites of bacterial activity are the crop and the ceca and to the lesser extent, the small intestine. These bacteria produce various metabolites using diets that can be beneficial or harmful to the host. Role of microbiota on the physiological, developmental, nutritional, and immunological processes of the host, leads to a beneficial effect on host gut health, performance and well-being of poultry birds in a range of aspects. Beneficial bacteria can protect the host from pathogenic bacteria by the different competitive mechanism. These bacteria are also involved in the development of the intestinal immune system. Microbiota can be a significant hindrance to growth performance due to enormous losses of proteins and high expenditure of metabolic energy. They can also have a negative impact on vitamin nutrition. Thus, modulating gut microbiota is very important in the post-antibiotic era. As reviewed in this paper, alternatives to antibiotics such as probiotics, prebiotics, organic acids, and exogenous enzyme tend to modulate gut microbiota. After in-depth understanding of the role of these dietary supplements on the overall performance of poultry, the next steps would be to identify alternative sources (plant, animal or other origins) rich in these supplements. Moreover, studies focused on the combination of these feed additives for their synergistic and agonistic approach may contribute to filling the gap of information on their combined effects.

\section{Abbreviations \\ AGP: Antibiotic growth promoter; CFU: Colony forming unit; DFM: Direct-fed microbial; FOS: Fructooligosaccharides; GIT: Gastro-intestinal tract; \\ IgG: Immunoglobulin G; LAB: Lactic acid bacteria; MC: Microbial community; MOS: Mannanoligosaccharides; RDP: Ribosomal database project: \\ SBM: Soybean meal; SCFA: Short chain fatty acid; TRFLP: Terminal restriction fragment length polymorphism; US: United States; WS-NSP: Water-soluble non-starch polysaccharides}

\section{Acknowledgments \\ Not applicable.}

\section{Funding}

Graduate student Sudhir Yadav was supported by USDA National Institute for Food and Agriculture, Hatch/Smith Lever Project HAW02030-H, managed by the College of Tropical Agriculture and Human Resources, University of Hawaii at Manoa, Honolulu, HI USA.

\section{Availability of data and materials None.}

\section{Authors contribution}

SY-Conceptualized the paper, compiled all the information and prepared the manuscript. RJ-Conceptualized the paper, provided insight to the overall manuscript and contributed in writing. Both authors read and approved the final manuscript.

Ethics approval and consent to participate Not applicable. 


\section{Consent for publication}

Not applicable.

\section{Competing interests}

The authors declare that they have no competing interests.

\section{Received: 24 October 2018 Accepted: 27 December 2018} Published online: 15 January 2019

\section{References}

1. Jha R, Berrocoso JD. Dietary fiber utilization and its effects on physiological functions and gut health of swine. Animal. 2015;9(9):1441-52.

2. Zhu XY, Zhong T, Pandya Y, Joerger RD. $16 \mathrm{~S}$ rRNA-based analysis of microbiota from the cecum of broiler chickens. Appl Environ Microbiol. 2002;68(1):124-37.

3. Apajalahti $\mathrm{JH}$, Kettunen $\mathrm{H}$, Kettunen $\mathrm{A}$, Holben WE, Nurminen $\mathrm{PH}$, Rautonen $\mathrm{N}$, et al. Culture-independent microbial community analysis reveals that inulin in the diet primarily affects previously unknown bacteria in the mouse cecum. Appl Environ Microbiol. 2002;68(10):4986-95.

4. Apajalahti J, Bedford M. Impact of dietary and environmental factors on microbial communities of the avian GI tract. Montreal, Canada: In Proceedings of the World's Poultry Congress; 2000

5. Aland A, Madec F. Sustainable animal production. Wageningen: Wageningen Academic Publishers; 2009.

6. Savage DC. Microbial ecology of the gastrointestinal tract. Annu Rev Microbiol. 1977;31(1):107-33.

7. Ewing WN, Cole DJ. Micro-flora of the gastro-intestinal tract. The living gut An introduction to micro-organisms in nutrition. 1994:45-65.

8. Gaskins HR. Intestinal bacteria and their influence on swine growth. Swine Nutrition. 2001;2:585-608.

9. Oviedo-Rondón EO, Hume ME, Hernandez C, Clemente-Hernández S. Intestinal microbial ecology of broilers vaccinated and challenged with mixed Eimeria species and supplemented with essential oil blends. Poult Sci. 2006;85(5):854-60

10. Knarreborg A, Simon MA, Engberg RM, Jensen BB, Tannock GW. Effects of dietary fat source and subtherapeutic levels of antibiotic on the bacterial community in the ileum of broiler chickens at various ages. Appl Environ Microbiol. 2002:68(12):5918-24.

11. Lu J, Idris U, Harmon B, Hofacre C, Maurer JJ, Lee MD. Diversity and succession of the intestinal bacterial community of the maturing broiler chicken. Appl Environ Microbiol. 2003;69(11):6816-24

12. Apajalahti J, Kettunen A, Graham $\mathrm{H}$. Characteristics of the gastrointestina microbial communities, with special reference to the chicken. Worlds Poult Sci J. 2004;60(2):223-32.

13. Kelly D, bacteria KTPL. Regulation of gut function and immunity. Gut Environment of Pigs. A. Piva, KE Bach Knudsen, and JE Lindberg. Nottingham, UK: Nottingham University Press; 2001. p. 113-31.

14. Suzuki K, Kodama Y, Mitsuoka T. Stress and intestinal flora. Bifidobacteria and microflora. 1989:8(1):23-38.

15. Mathlouthi N, Mallet S, Saulnier L, Quemener B, Larbier M. Effects of xylanase and $\alpha$-glucanase addition on performance, nutrient digestibility, and physico-chemica conditions in the small intestine contents and caecal microflora of broiler chickens fed a wheat and barley-based diet. Anim Res. 2002;51(05):395-406.

16. Cherbut C. Motor effects of short-chain fatty acids and lactate in the gastrointestinal tract. Proc Nutr Soc. 2003;62(1):95-9.

17. Schokker D, Jansman AJ, Veninga G, De Bruin N, Vastenhouw SA, de Bree FM, et al. Perturbation of microbiota in one-day old broiler chickens with antibiotic for 24 hours negatively affects intestinal immune development. BMC Genomics. 2017;18(1):241

18. Lan PT, Hayashi H, Sakamoto M, Benno Y. Phylogenetic analysis of cecal microbiota in chicken by the use of 165 rDNA clone libraries. Microbiol Immunol. 2002:46(6):371-82.

19. Barnes EM. The intestinal microflora of poultry and game birds during life and after storage. J Appl Microbiol. 1979:46(3):407-19.

20. Gong J, Forster RJ, Yu H, Chambers JR, Wheatcroft R, Sabour PM, et al. Molecular analysis of bacterial populations in the ileum of broiler chickens and comparison with bacteria in the cecum. FEMS Microbiol Ecol. 2002; 41(3):171-9.

21. Marchesi JR, Ravel J. The vocabulary of microbiome research: a proposal. 2015.
22. Shaufi MA, Sieo CC, Chong CW, Gan HM, Ho YW. Deciphering chicken gut microbial dynamics based on high-throughput $16 \mathrm{~S}$ rRNA metagenomics analyses. Gut Pathogens. 2015;7(1):4.

23. Borda-Molina D, Seifert J, Camarinha-Silva A. Current Perspectives of the Chicken Gastrointestinal Tract and Its Microbiome. Comput Struct Biotechnol J. 2018;16:131-9.

24. Stanley D, Geier MS, Hughes RJ, Denman SE, Moore RJ. Highly variable microbiota development in the chicken gastrointestinal tract. PLoS One. 2013:8(12):e84290.

25. Wei S, Morrison M. Yu Z. Bacterial census of poultry intestinal microbiome. Poult Sci. 2013:92(3):671-83.

26. Albazaz R, Bal EB. Microflora of digestive tract in poultry. Doga Bilimleri Dergisi. 2014;17(1):39.

27. Choct M. Managing gut health through nutrition. Br Poult Sci. 2009;50(1):9-15.

28. Yeoman CJ, Chia N, Jeraldo P, Sipos M, Goldenfeld ND, White BA. The microbiome of the chicken gastrointestinal tract. Anim Health Res Rev. 2012;13(1):89-99.

29. Borda-Molina D, Vital M, Sommerfeld V, Rodehutscord M, Camarinha-Silva A. Insights into broilers' gut microbiota fed with phosphorus, calcium, and phytase supplemented diets. Front Microbiol. 2016;7:2033.

30. Rinttilä T, Apajalahti J. Intestinal microbiota and metabolites-Implications for broiler chicken health and performance1. J Appl Poult Res. 2013;22(3): 647-58.

31. Savage DC. Gastrointestinal microflora in mammalian nutrition. Annu Rev Nutr. 1986;6(1):155-78.

32. Snel J, Harmsen HJ, Van der Wielen PW, Williams BA. Dietary strategies to influence the gastrointestinal microflora of young animals, and its potential to improve intestinal health. Nutr Health Gastrointest tract 2002:37-69.

33. van der Wielen PW, Biesterveld S, Notermans S, Hofstra H, Urlings BA, van Knapen F. Role of volatile fatty acids in development of the cecal microflora in broiler chickens during growth. Appl Environ Microbiol. 2000;66(6):2536-40.

34. De Vadder F, Kovatcheva-Datchary P, Goncalves D, Vinera J, Zitoun C, Duchampt A, et al. Microbiota-generated metabolites promote metabolic benefits via gut-brain neural circuits. Cell. 2014;156(1):84-96.

35. AL-Darkazali H, Meevootisom V, Isarangkul D, Gene Expression WS. Molecular Characterization of a Xylanase from Chicken Cecum Metagenome. Int J Microbiol. 2017.

36. Van der Waaij D, Berghuis-de Vries JM, Lekkerkerk-Van der Wees JE. Colonization resistance of the digestive tract in conventional and antibiotictreated mice. Epidemiol Infect. 1971;69(3):405-11.

37. Naidu AS, Bidlack WR, Clemens RA. Probiotic spectra of lactic acid bacteria (LAB). Crit Rev Food Sci Nutr. 1999;39(1):13-26.

38. Schaffner T, Mueller J, Hess MW, Cottier H, Sordat B, Ropke C. The bursa of Fabricius: a central organ providing for contact between the lymphoid system and intestinal content. Cell Immunol. 1974;13(2):304-12.

39. Ekino S, Nawa Y, Tanaka K, Matsuno K, Fujii H, Kotani M. Suppression of immune response by isolation of the bursa of Fabricius from environmental stimuli. Immunol Cell Biol. 1980;58(3):289-96.

40. Lei YM, Nair L, Alegre ML. The interplay between the intestinal microbiota and the immune system. Clin Res Hepatol Gastroenterol. 2015;39(1):9-19.

41. Jha $\mathrm{R}$, Berrocoso JF. Dietary fiber and protein fermentation in the intestine of swine and their interactive effects on gut health and on the environment: A review. Anim Feed Sci Technol. 2016;212:18-26.

42. Van der Klis JD, Jansman AJ. Optimising nutrient digestion, absorption and gut barrier function in monogastrics: Reality or illusion. Nutr Health Gastrointest tract 2002:15-36.

43. Apajalahti J, Vienola K. Interaction between chicken intestinal microbiota and protein digestion. Anim Feed Sci Technol. 2016;221:323-30.

44. Eyssen $\mathrm{H}$, De Somer $\mathrm{P}$. The mode of action of antibiotics in stimulating growth of chicks. J Exp Med. 1963:117(1):127.

45. Gaskins HR, Collier CT, Anderson DB. Antibiotics as growth promotants: mode of action. Anim Biotechnol. 2002:13(1):29-42.

46. Abrams GD, Bauer $H$, Sprinz $H$. Influence of the normal flora on mucosal morphology and cellular renewal in the ileum. In: A comparison of germfree and conventional mice. New York, NY USA: Mount Sinai hospital; 1962.

47. Coates ME. Gut microflora and growth. Growth in animals. Edited by TLJ Lawrence. 1980

48. Summers, M. Energy metabolism in the broiler chick. Ph. D. Thesis. University of Guelph, Ontario, Canada; 1991.

49. Cant JP, McBride BW, Croom WJ. The regulation of intestinal metabolism and its impact on whole animal energetics. J Anim Sci. 1996;74:2541-53. 
50. Thorbecke GJ, Gordon HA, Wostman B, Wagner M, Reyniers J. Lymphoid tissue and serum gamma globulin in young germfree chickens. J Infect Dis. 1957:237-51.

51. Macpherson AJ, Gatto D, Sainsbury E, Harriman GR, Hengartner H, Zinkernagel RM. A primitive T cell-independent mechanism of intestinal mucosal IgA responses to commensal bacteria. Science. 2000;288(5474):2222-6.

52. Thompson K, Applegate TJ. Nutrients, nutritional state and small intestinal microbiota. In: Nutrients, Nutritional State, and Small Intestinal Microbiota. Raleigh, NC, USA: 32nd Annual Carolina Poultry Nutrition Conference, Research Triangle Park, NC. Carolina Feed Industry Association/North Carolina State University; 2005. p. 28-37.

53. Oviedo-Rondón EO, Hume ME. Equilibrium in the gut ecosystem for productive healthy birds. In Proceedings of the Arkansas Nutrition Conference. Rogers, AR, USA. September 4-5, 2013 (pp. 1-18).

54. Izquierdo JA, Sizova MV, Lynd LR. Diversity of bacteria and glycosyl hydrolase family 48 genes in cellulolytic consortia enriched from thermophilic biocompost. Appl Environ Microbiol. 2010;76(1 1):3545-53.

55. Stanley D, Geier MS, Denman SE, Haring VR, Crowley TM, Hughes RJ, et al. Identification of chicken intestinal microbiota correlated with the efficiency of energy extraction from feed. Vet Microbiol. 2013;164(1-2):85-92.

56. Ley RE, Turnbaugh PJ, Klein S, Gordon Jl. Microbial ecology: human gut microbes associated with obesity. Nature. 2006;444(7122):1022.

57. Pan D, Yu Z. Intestinal microbiome of poultry and its interaction with host and diet. Gut Microbes. 2014;5(1):108-19.

58. Gustafson RH, Bowen RE. Antibiotic use in animal agriculture. J Appl Microbiol. 1997;83(5):531-41.

59. Oliver SP, Murinda SE, Jayarao BM. Impact of antibiotic use in adult dairy cows on antimicrobial resistance of veterinary and human pathogens: a comprehensive review. Foodborne Pathog Dis. 2011;8(3):337-55.

60. Wisselink HJ, Cornelissen JB, Mevius DJ, Smits MA, Smidt H, Rebel JM. Antibiotics in 16-day-old broilers temporarily affect microbial and immune parameters in the gut. Poult Sci. 2017;96(9):3068-78.

61. Niewold TA. The nonantibiotic anti-inflammatory effect of antimicrobial growth promoters, the real mode of action? A hypothesis. Poult Sci. 2007;86(4):605-9.

62. Lalles JP, Boudry G, Favier C, Le Floc'h N, Luron I, Montagne L, et al. Gut function and dysfunction in young pigs: physiology. Anim Res. 2004;53(4):301-16.

63. Huyghebaert $G$, Ducatelle R, Van Immerseel F. An update on alternatives to antimicrobial growth promoters for broilers. Vet J 2011;187(2):182-188.

64. Food and Agricultural Organization of the United Nations and World Health Organization. Joint FAO/WHO working group report on drafting guidelines for the evaluation of probiotics in food. 2002.

65. Huang MK, Choi YJ, Houde R, Lee JW, Lee B, Zhao X. Effects of Lactobacilli and an acidophilic fungus on the production performance and immune responses in broiler chickens. Poult Sci. 2004;83(5):788-95.

66. Hossain ME, Kim GM, Lee SK, Yang CJ. Growth performance, meat yield oxidative stability, and fatty acid composition of meat from broilers fed diets supplemented with a medicinal plant and probiotics. Asian Australas J Anim Sci. 2012;25(8):1159.

67. Singh AK, Berrocoso JD, Dersjant-Li Y, Awati A, Jha R. Effect of supplemental multi-enzymes and direct-fed microbial on nutrients digestibility in broilers fed low and high fiber diets. Poult Sci. 2015;94(E-suppl. 1):9

68. Waititu SM, Yitbarek A, Matini E, Echeverry H, Kiarie E, Rodriguez-Lecompte JC, Nyachoti CM. Effect of supplementing direct-fed microbials on broiler performance, nutrient digestibilities, and immune responses. Poult Sci. 2014; 93(3):625-35.

69. Kalia S, Bharti VK, Gogoi D, Giri A, Kumar B. Studies on the growth performance of different broiler strains at high altitude and evaluation of probiotic effect on their survivability. Sci Rep. 2017;7:460-74.

70. Wang Y, Sun J, Zhong H, Li N, Xu H, Zhu Q, et al. Effect of probiotics on the meat flavour and gut microbiota of chicken. Sci Rep. 2017;7(1):6400.

71. Brisbin JT, Gong J, Parvizi P, Sharif S. Effects of lactobacilli on cytokine expression by chicken spleen and cecal tonsil cells. Clin Vaccine Immunol. 2010;17(9):1337-43.

72. Cengiz Ö, Köksal BH, Tatı O, Sevim Ö, Ahsan U, Üner AG, et al. Effect of dietary probiotic and high stocking density on the performance, carcass yield, gut microflora, and stress indicators of broilers. Poult Sci. 2015;94(10):2395-403.

73. Bai SP, Wu AM, Ding XM, Lei Y, Bai J, Zhang KY, et al. Effects of probioticsupplemented diets on growth performance and intestinal immune characteristics of broiler chickens. Poult Sci. 2013;92(3):663-70.

74. Li LL, Hou ZP, Li TJ, Wu GY, Huang RL, Tang ZR, et al. Effects of dietary probiotic supplementation on ileal digestibility of nutrients and growth performance in 1-to 42-day-old broilers. J Sci Food Agric. 2008;88(1):35-42.
75. Teng PY, Kim WK. Roles of prebiotics in intestinal ecosystem of broilers. Frontiers in Veterinary Science. 2018;5:245.

76. Alloui MN, Szczurek W, Świątkiewicz S. The usefulness of prebiotics and probiotics in modern poultry nutrition: A review/Przydatność prebiotyków i probiotyków w nowoczesnym żywieniu drobiu-przegląd. Ann Anim Sci. 2013;13(1):17-32.

77. Ganguly S. Supplementation of prebiotics, probiotics and acids on immunity in poultry feed: a brief review. Worlds Poult. Sci. J. 2013;69(3):639-48.

78. Kim GB, Seo YM, Kim CH, Paik IK. Effect of dietary prebiotic supplementation on the performance, intestinal microflora, and immune response of broilers. Poult Sci. 2011;90(1):75-82.

79. Sugiharto $S$. Role of nutraceuticals in gut health and growth performance of poultry. J Saudi Soc Agric Sci. 2016;15(2):99-111.

80. Micciche AC, Foley SL, Pavlidis HO, McIntyre DR, Ricke SCA. Review of Prebiotics Against Salmonella in Poultry: Current and Future Potential for Microbiome Research Applications. Front Vet Sci. 2018;5:191.

81. Ricke SC. Perspectives on the use of organic acids and short chain fatty acids as antimicrobials. Poult Sci. 2003;82(4):632-9.

82. Saki AA, Harcini RN, Rahmatnejad E, Salary J. Herbal additives and organic acids as antibiotic alternatives in broiler chickens diet for organic production. Afr J Biotechnol. 2012;11(8):2139-45.

83. Moquet, Pierre CA. Butyrate in broiler diets: impact of butyrate presence in distinct gastrointestinal tract segments on digestive function, microbiota composition and immune responses. PhD diss., Wageningen University. 2018. ISBN: 9789463437745.

84. Gauthier R. Intestinal health, the key to productivity: The case of organic acids. IASA XXVII convencion ANECA-WPDC. Puerto Vallarta, Mexico. 2002.

85. Adil S, Banday MT, Bhat GA, Qureshi SD, Wani SA. Effect of supplemental organic acids on growth performance and gut microbial population of broiler chicken. Livest Res Rural Dev. 2011;23(1):1-8.

86. Smulikowska S, Czerwiński J, Mieczkowska A. Effect of an organic acid blend and phytase added to a rapeseed cake-containing diet on performance, intestinal morphology, caecal microflora activity and thyroid status of broiler chickens. J Anim Physiol Anim Nutr. 2010;94(1):15-23.

87. Adeola O, Cowieson AJ. Board-invited review: Opportunities and challenges in using exogenous enzymes to improve nonruminant animal production. J Anim Sci. 2011;89(10):3189-218.

88. Costa FG, Goulart CC, Figueiredo DF, Oliveira CF, Silva JH. Economic and environmental impact of using exogenous enzymes on poultry feeding. Int J Poult Sci. 2008;7(4):311-4.

89. Jha R, Woyengo TA, Li J, Bedford MR, Vasanthan T, Zijlstra RT. Enzymes enhance degradation of the fiber-starch-protein matrix of distillers dried grains with solubles as revealed by a porcine in vitro fermentation model and microscopy. J Anim Sci. 2015;93(3):1039-51.

90. Singh AK, Berrocoso JD, Dersjant-Li Y, Awati A, Jha R. Effect of a combination of xylanase, amylase and protease on growth performance of broilers fed low and high fiber diets. Anim Feed Sci Technol. 2017:232:16-20.

91. Józefiak D, Kaczmarek S, Rutkowski A, Józefiak A, Jensen BB, Engberg RM. Fermentation in broiler chicken gastrointestinal tract as affected by high dietary inclusion of barley and beta-glucanase supplementation. J Anim Feed Sci. 2005;14(4):695.

92. Torok VA, Ophel-Keller K, Loo M, Hughes RJ. Application of methods for identifying broiler chicken gut bacterial species linked with increased energy metabolism. Appl Environ Microbiol. 2008;74(3):783-91.

93. Yang Y, lji PA, Kocher A, Mikkelsen LL, Choct M. Effects of xylanase on growth and gut development of broiler chickens given a wheat-based diet. Asian Australas J Anim Sci. 2008;21(11):1659-64.

94. Cowieson AJ, Roos FF. Toward optimal value creation through the application of exogenous mono-component protease in the diets of nonruminants. Anim Feed Sci Technol. 2016:221:331-40.

95. Bedford MR, Cowieson AJ. Exogenous enzymes and their effects on intestinal microbiology. Anim Feed Sci Technol. 2012;173(1-2):76-85.

96. Kiarie E, Romero LF, Nyachoti CM. The role of added feed enzymes in promoting gut health in swine and poultry. Nutr Res Rev. 2013;26(1):71-88.

97. Ravindran V. Feed enzymes: The science, practice, and metabolic realities. J Appl Poult Res. 2013;22(3):628-36.

98. Wang L, Lilburn M. Yu Z. Intestinal microbiota of broiler chickens as affected by litter management regimens. Front Microbiol. 2016;7:593.

99. Witzig M, da Silva AC, Green-Engert R, Hoelzle K, Zeller E, Seifert J, et al. Spatial variation of the gut microbiota in broiler chickens as affected by dietary available phosphorus and assessed by T-RFLP analysis and 454 pyrosequencing. PLoS One. 2015;10(11):e0143442. 